\title{
ANALISIS KLASTER UKM KERIPIK GADUNG DI KABUPATEN TULUNGAGUNG
}

\section{Cluster Analysis of Gadung Chips SMEs in Tulungagung Regency}

\author{
Oni Zakiyah*, Siti Asmaul Mustaniroh, Retno Astuti \\ Jurusan Teknologi Industri Pertanian - Fakultas Teknologi Pertanian - Universitas Brawijaya \\ Jl. Veteran - Malang 65145 \\ *Penulis Korespondensi: email: onizakiyah13@gmail.com
}

Disubmit: 4 September 2018 Direvisi: 27 Maret 2019 Diterima: 30 Maret 2019

\begin{abstract}
ABSTRAK
Keripik gadung merupakan salah satu produk unggulan daerah Kabupaten Tulungagung, sentra produksi keripik gadung terletak di Kecamatan Kalidawir dengan jumlah 25 UKM yang masih aktif produksi. Kapasitas produksi yang dihasilkan UKM rata-rata sebesar $5.416 \mathrm{~kg}$ per bulan. Permasalahan yang dialami UKM selama ini adalah kelembagaan masih cenderung individu sehingga minimnya komunikasi dan kerjasama antar UKM, belum ada asosiasi dan kerjasama dengan pemerintah serta rendahnya kualitas produk. Tujuan penelitian adalah menganalisis clustering UKM keripik gadung berdasarkan kinerja dan kualitas produk. Metode yang digunakan pada penelitian adalah K-means clustering. Hasil penelitian membentuk 2 klaster. Klaster 1 terdiri dari 11 anggota UKM skala kecil dan klaster 2 terdiri dari 14 anggota UKM skala usaha mikro. Pada klaster 1 dan 2 perbedaan signifikan terletak pada nilai kapasitas produksi, jumlah investasi, jumlah tenaga kerja, rata-rata penjualan dan pendapatan. Usulan perbaikan yang dapat dilakukan klaster 1 untuk mengembangkan usaha melalui peningkatan akses informasi dan peningkatan inovasi teknologi, sedangkan klaster 2 melalui peningkatan permodalan agar dapat melakukan kegiatan pemasaran dengan optimal, meningkatkan kapasitas produksi serta memperbaiki kualitas produk yang dihasilkan. Penerapan standarisasai, quality control (QC) dan peningkatan akses pemasaran juga diperlukan untuk mengembangkan usaha keripik gadung. Upaya perbaikan melibatkan seluruh pelaku dan pemerintah daerah yang saling terhubung
\end{abstract}

Kata kunci: Klaster; Keripik Gadung; K-Means Cluster

\begin{abstract}
Gadung Chips is one of the superior products in the Tulungagung Regency, Gadung chips production center is located in Kalidawir District with 25 SMEs which are still actively producing. The production capacity produced by SMEs is an average of $5.416 \mathrm{~kg}$ per month. The problem experienced by SMEs is that institutions still tend to be individuals so there is a lack of communication and cooperation between $S M E s$. There is no association and cooperation with the Government and low quality products. The aim of the study was to clustering analyze of gadung chips SMEs based on performance and product quality. The method used in the study is K-means clustering. The results of the study used the K-means clustering method to form 2 clusters. Cluster 1 consists of 11 small-scale SMEs members and cluster 2 consists of 14 micro business scale SMEs. In cluster 1 and 2 the significant difference lies in the value of production capacity, amount of investment, number of workers, average sales and income. Proposed improvements that can be made in cluster 1 to develop the business through increasing access to information and increasing technological innovation while cluster 2 through increasing capital in order to be able to carry out marketing activities optimally, increase production capacity and improve the quality of the products produced. Standardization, quality control (QC) and increased access to marketing are also needed to develop the gadung chips business. Improvement efforts involve all actors and local governments that are interconnected
\end{abstract}

Keyword: Clustering; Gadung Chips; K-Means Cluster 


\section{PENDAHULUAN}

Kabupaten Tulungagung merupakan salah satu kabupaten di Jawa Timur yang memiliki potensi di sektor pertanian. Wilayah Kabupaten Tulungagung merupakan bagian dari pegunungan kapur selatan Jawa Timur yang mencakup areal seluas $\pm 40 \%$ (Bappeda Jawa Timur, 2018). Daerah kapur potensi untuk ditanami jenis tanaman palawija salah satunya adalah umbi gadung (Djafar, 2013). Umbi gadung diolah menjadi produk keripik gadung dan dijadikan sebagai produk unggulan daerah yang dikembangkan oleh UKM di Kabupaten Tulungagung. Pemerintah Kabupaten Tulungagung berupaya mengembangkan UKM dan sentra-sentra industri potensial agar dapat meningkatkan ekonomi daerah di Kabupaten Tulungagung melalui penerapan konsep One Village One Product (OVOP). Konsep OVOP merupakan suatu gerakan revitalisasi daerah dan salah satu pendekatan menuju klasterisasi produk unggulan agar dapat berkembang dan mengakses pasar secara lebih luas (Schumann, 2016).

Kecamatan Kalidawir salah satu sentra utama produksi keripik gadung mentah yang memiliki potensi cukup besar untuk dikembangkan. Pengembangan usaha keripik gadung di Kecamatan Kalidawir memiliki beberapa kendala dari segi kinerja dan kualitas, diantaranya kelembagaan masih cenderung individu, belum ada asosiasi dan kerjasama dengan Pemerintah, kegiatan pemasaran yang terbatas serta rendahnya kualitas produk. Kinerja merupakan laju pertumbuhan atau keberhasilan selama periode tertentu (Genty, 2015). Pengukuran kinerja dapat dilihat dari segi keuangan (modal, laba, pendapatan) atau kegiatan non finansial (pertumbuhan penjualan, tenaga kerja) (Maduekwe dan Kamala 2016; Richard et al., 2009). Kualitas produk merupakan suatu hal yang penting dalam menentukan pemilihan suatu produk oleh konsumen. Kualitas produk perlu diperhatikan agar mutu dan reputasi perusahaan tetap terjaga dengan memberikan kepuasan konsumen (Yee et al., 2010). Salah satu solusi untuk meningkatkan daya saing industri di daerah melalui pengembangan klaster industri (Porter, 1998).

Pembentukan klaster merupakan elemen penting dari kebijakan pengembangan potensi inovatif dari setiap wilayah sehing- ga dapat meningkatkan daya saing daerah (Arzhakov dan Silnov, 2016). Model klaster mampu membangun jaringan kerjasama yang saling menguntungkan antar UKM sejenis (Zhukov et al., 2016). Keuntungan ini memungkinkan anggota klaster menjadi lebih produktif dan inovatif (Bogdanova dan Lemetti, 2011). Penelitian tentang pengembangan dan pembentukan cluster telah banyak dilakukan, antara lain oleh Akhmad dan Hidayat (2014) hasil penelitian pada UKM batik di Bangkalan menggunakan metode $K$ means menghasilkam 3 kelompok usaha kecil menengah, 15 IKM masuk usaha kecil, 9 IKM usaha menengah dan 22 IKM usaha mikro atau rumah tangga. Penelitian lain oleh Karelakis et al. (2008), menggunakan metode AHP dan K-means menghasilkan 3 kelompok. Klaster 1 terdiri 24 perusahaan anggur yang mencapai kinerja eksportir tingkat menengah dan tinggi dengan strategi promosi yang memadai tanpa hambatan distribusi atau transportasi, klaster 2 terdiri 35 perusahaan memiliki kinerja eksportir kurang memadai dan klaster 3 terdiri 51 perusahaan berada di posisi tengah dan tidak ditemui masalah sosio-budaya di pasar ekspor.

Berdasarkan permasalahan yang dihadapi UKM keripik gadung di Kabupaten Tulungagung maka penelitian ini bertujuan mengelompokkan (clustering) UKM berdasarkan kinerja dan kualitas produk dengan metode $\mathrm{K}$-means clustering. Penggunaan metode K-means clustering memiliki kelebihan ketelitian yang cukup tinggi terhadap ukuran objek, sehingga algoritma relatif lebih besar. Kelemahan algoritma K-means clustering di antaranya tergantung pada pemilihan nilai awal centroid dan tidak jelas berapa banyak jumlah klaster yang terbentuk (Jain, 2010). Akademik dan pakar ahli pada penelitian ini berperan memberikan usulan perbaikan pengembangan usaha yang tepat dan sesuai dengan kondisi masing-masing klaster.

\section{METODE}

Penelitian dilakukan di UKM keripik gadung Kecamatan Kalidawir, Kabupaten Tulungagung. Variabel yang digunakan pada penelitian dapat dilihat ada Tabel 1. Metode analisis yang digunakan adalah K-means clustering. Jumlah sampel yang diambil sebesar 
25 unit UKM keripik gadung di Desa Joho Kecamatan Kalidawir. Sumber data yang digunakan adalah data primer dan sekunder. Data primer diperoleh melalui wawancara, kuesioner dan observasi. Data sekunder diperoleh dari data Dinas Perindustrian, Badan Pusat Statistik (BPS) dan beberapa jurnal yang mendukung. Teknik pengambilan sampel menggunakan sampling jenuh (saturation sampling).

Responden terdiri dari 25 Pemilik UKM, 30 konsumen, dan 3 pakar ahli. Pemilik sebagai responden dalam penilaian kinerja. Responden konsumen menilai masing-masing kualitas produk yang dihasilkan UKM. Pakar ahli sebagai responden dalam penentuan usulan perbaikan pengembangan usaha.

Penentuan jumlah klaster dilakukan terlebih dahulu menggunakan metode elbow. Metode elbow dalam analisis klaster untuk interpretasi dan uji performa tingkat konsistensi jumlah klaster yang tepat dengan melihat nilai Sum Square Error (SSE). Pada titik tertentu akan terjadi grafik penurunan secara dramatis dengan lekukan yang disebut dengan kriteria siku. Nilai tersebut menjadi nilai $k$ atau jumlah klaster yang terbaik (Bholowalia dan Kumar, 2014). Tools yang digunakan dalam analisis klaster adalah software Rstudio dan SPSS 17.0.

\section{HASIL DAN PEMBAHASAN}

\section{Gambaran Umum UKM keripik Gadung di Kecamatan Kalidawir}

Sentra produksi keripik gadung terletak di Desa Joho Kecamatan Kalidawir sebelah ujung selatan Kabupaten Tulungagung. Luas wilayah Kecamatan Kalidawir sebesar $97.43 \mathrm{~km}^{2}$ yang sebagian wilayahnya pegunungan (BPS, 2018). Tanaman umbi gadung realatif tumbuh di daerah pegunungan kapur bagian selatan Kabupaten Tulungagung, sebagian besar masyarakat setempat mata pencaharian sebagai produsen keripik gadung. Jumlah UKM keripik gadung yang aktif produksi sebesar 25 UKM dengan lokasi yang berdekatan di satu desa.

Sentra keripik gadung berpotensi dikembangkan karena sudah berjalan sejak lama, bisnis turun temurun, dekat dengan sumber bahan baku dan memiliki ketersediaan jumlah tenaga kerja. Kapasitas produksi yang dihasilkan rata-rata sekitar $5.416 \mathrm{~kg}$ per bulan. Bahan baku didapatkan dari petani lokal di Tulungagung dan beberapa wilayah lainnya seperti Trenggalek, Blitar, Madiun, dan Jawa Tengah.

Proses produksi keripik gadung membutuhkan waktu cukup lama sekitar 6-7 hari dalam sekali produksi karena umbi gadung memiliki senyawa antinutrisi seperti dioskorin, histamine, saponin dan glukosida sianogenik yang mengandung racun dan tidak aman jika langsung dikonsumsi. Produsen keripik gadung menerapkan metode penghilangan sianida dalam umbi gadung seperti perendaman dalam larutan garam dapur, perendaman dengan air mengalir, pemberian abu gosok, pengepresan atau perlakuan panas (penjemuran dan perebusan umbi) (Sunarsih et al., 2007). Di Malaysia umbi gadung dapat didetoksifikasi secara tradisional dengan perebusan, pemanggangan atau perendaman air mengalir selama 7 hari (Hudzari et al., 2011). Oleh karena itu, pembuatan keripik gadung membutuhkan waktu yang cukup lama sehingga produsen keripik gadung di Kabupaten Tulungagung hanya menghasilkan produk mentah atau belum digoreng.

Kegiatan produksi keripik gadung dilakukan pada musim kemarau sekitar bulan Juni-Agustus karena sifat bahan baku yang musiman. Panen umbi gadung hanya terjadi tiga kali dalam setahun, ditanam pada awal atau akhir musim hujan, tergantung pada kultivar dan jangka waktu pertumbuhan kematangan karena tanaman ini tidak ekonomis atau tidak umum di tanam di areal yang beririgasi (Webster et al., 1984). Tanaman umbi gadung tumbuh dan berkembang dengan baik di iklim tropis (Trimanto dan Hapsari, 2015).

Klaster industri keripik gadung di Kecamatan Kalidawir memiliki peluang untuk dikembangkan dalam upaya peningkatan perekonomian daerah dengan adanya inisiasi dari Pemerintah Provinsi Jawa Timur melalui konsep One Village One Product (OVOP). Konsep OVOP mengutamakan produk unik yang ada disetiap daerah, masing-masing daerah mengidentifikasi satu atau dua produk (barang atau jasa) untuk membentuk suatu produk yang khas dari hasil lokal daerah tersebut (Schumann, 2016). Pengembangan OVOP melalui peningkatan ketrampilan kewirausahaan masyarakat lokal dengan memanfaatkan sumber daya, pengetahuan 
Jurnal Teknologi Pertanian Vol. 20 No. 1 [April 2019] 53-66

Analisis Klaster UKM Keripik Gadung [Zakiyah dkk]

Tabel 1. Variabel penelitian

\begin{tabular}{|c|c|c|c|c|c|}
\hline \multirow{2}{*}{\multicolumn{2}{|c|}{ Simbol }} & \multicolumn{4}{|c|}{ Variabel } \\
\hline & & \multicolumn{4}{|c|}{ Kinerja UKM } \\
\hline & $\mathrm{X} 1$ & \multicolumn{4}{|c|}{ Lama usaha (tahun) } \\
\hline & $\mathrm{X} 2$ & \multicolumn{4}{|c|}{ Kapasitas produksi (kg/bulan) } \\
\hline & $\mathrm{X} 3$ & \multicolumn{4}{|c|}{ Jumlah tenaga kerja (orang) } \\
\hline & $\mathrm{X} 4$ & \multicolumn{4}{|c|}{ Nilai investasi awal (Rp) } \\
\hline & X5 & \multicolumn{4}{|c|}{ Rata-rata penjualan (kg/bulan) } \\
\hline & X6 & \multicolumn{4}{|c|}{ Rata-rata pendapatan (Rp/bulan) } \\
\hline & $\mathrm{X} 7$ & \multicolumn{4}{|c|}{ Jumlah keluhan pelanggan (per bulan) } \\
\hline & $\mathrm{X} 8$ & \multicolumn{4}{|c|}{ Jumlah cacat produk (g/tiap produksi) } \\
\hline & X9 & \multicolumn{4}{|c|}{ Jumlah wilayah pemasaran } \\
\hline & & \multicolumn{4}{|c|}{ Kualitas produk } \\
\hline & Y1 & \multicolumn{4}{|c|}{ Kinerja (Performance) } \\
\hline & $\mathrm{Y} 2$ & \multicolumn{4}{|c|}{ Keandalan (Reliability) } \\
\hline & Y3 & \multicolumn{4}{|c|}{ Keistimewaan tambahan (Feature) } \\
\hline & Y4 & \multicolumn{4}{|c|}{ Daya tahan (Durability) } \\
\hline \multicolumn{6}{|c|}{ Sumber: Mustaniroh et al. (2016); dan Garvin (1987) } \\
\hline \multicolumn{6}{|c|}{ Tabel 2. Karakteristik responden } \\
\hline No. & \multicolumn{2}{|c|}{ Karakteristik } & Mean & $\begin{array}{c}\text { Nilai } \\
\text { minimal }\end{array}$ & $\begin{array}{c}\text { Nilai } \\
\text { maksimal }\end{array}$ \\
\hline \multicolumn{6}{|c|}{ Kinerja UKM } \\
\hline 1. & \multicolumn{2}{|l|}{ Lama usaha } & 13 & 3 & 27 \\
\hline 2. & \multicolumn{2}{|c|}{ Kapasitas produksi } & 5.416 & 2.400 & 8.000 \\
\hline 3. & \multicolumn{2}{|c|}{ Jumlah tenaga kerja } & 7 & 3 & 15 \\
\hline 4. & \multicolumn{2}{|c|}{ Nilai Investasi awal (Rp) } & 39.050 .000 & 21.500 .000 & 53.000 .000 \\
\hline 5. & \multicolumn{2}{|c|}{ Rata-rata penjualan per bulan } & 444,44 & 200 & 660 \\
\hline 6. & Rata-rata pendap & an $(R p)$ & 21.440 .000 & 12.000 .000 & 32.000 .000 \\
\hline 7. & Jumlah keluhan $\mathrm{p}$ & & 3 & 2 & 5 \\
\hline 8. & Jumlah cacat proc & duksi & 356 & 200 & 500 \\
\hline 9. & Jumlah wilayah $\mathrm{p}$ & & 3 & 2 & 5 \\
\hline & Kualitas Produk & & & & \\
\hline 1. & Kinerja (Performar & & 3.91 & 2.77 & 4.61 \\
\hline 2. & Keandalan (Reliak & & 2.72 & 2.10 & 3.48 \\
\hline 3. & Keistimewaan tar & ure) & 2.52 & 1.72 & 3.32 \\
\hline 4. & Daya tahan (Dura & & 4.13 & 2.67 & 4.75 \\
\hline Tabel & 3. Hasil uji SSE & & & & \\
\hline & Jumlah Klaster & & & Sel & \\
\hline & 1 & & & & \\
\hline & 2 & & & 6.18 & \\
\hline & 3 & & & 3.41 & \\
\hline & 4 & & & 2.25 & \\
\hline
\end{tabular}


dan menciptakan kegiatan yang menambah nilai melalui branding produk lokal (Hirohata, 2013). Pengembangan klaster dapat membentuk spesialisasi produk, meningkatkan daya saing, mengurangi biaya, meningkatkan kualitas dan meningkatkan hubungan dalam hal distribusi, pengembangan produk dan pemasaran (Bernat et al., 1999).

UKM keripik gadung memiliki keterkaitan dengan beberapa pihak yang mendukung dalam kelancaran kegiatan industri. Pihak-pihak tersebut terdiri dari industri inti (UKM) dan pelaku-pelaku lain stakeholder (pemasok, industri pendukung, lembaga pendukung dan pembeli) yang mendukung keberlangsungan klaster UKM keripik gadung. Hal ini diperkuat oleh Porter (1998), mengidentifikasikan tiga kategori stakeholder dalam klaster yaitu pelaku inti, lembaga pendukung (supporting institutions) dan Pemerintah. Kelembagaan klaster UKM keripik gadung menunjukkan bahwa industri inti merupakan pelaku utama klaster industri. Industri pemasok berhubungan dengan industri inti sebagai penyedia bahan baku yang akan diproses menjadi produk keripik gadung. Industri pendukung sebagai penyedia peralatan dan mesin serta penyedia modal (Bank). Lembaga pendukung berhubungan dengan industri inti dalam menjaga stabilitas ekonomi, melakukan pembinaan dan pelatihan dalam pengembangan UKM dan membantu permodalan. Hubungan institusional dalam klaster meliputi teknologi, ketrampilan, informasi, pemasaran dan kebutuhan konsumen (Doncheva, 2016). Pen-

Tabel 4. Perbedaan karakteristik UKM masing-masing klaster

\begin{tabular}{|c|c|c|c|c|c|c|}
\hline \multirow[b]{2}{*}{ Karakteristik } & \multicolumn{3}{|c|}{ Klaster 1 (11 UKM) } & \multicolumn{3}{|c|}{ Klaster 2 (14 UKM) } \\
\hline & $\begin{array}{l}\text { Pusat } \\
\text { Klaster }\end{array}$ & Minimal & Maksimal & $\begin{array}{l}\text { Pusat } \\
\text { Klaster }\end{array}$ & Minimal & Maksimal \\
\hline \multicolumn{7}{|l|}{ Kinerja UKM } \\
\hline Lama Usaha & 16 & 6 & 27 & 12 & 3 & 20 \\
\hline $\begin{array}{l}\text { Kapasitas } \\
\text { produksi }\end{array}$ & 7000 & 6000 & 8000 & 4171 & 2400 & 6000 \\
\hline Tenaga Kerja & 11 & 5 & 15 & 5 & 3 & 9 \\
\hline $\begin{array}{l}\text { Nilai investasi } \\
\text { awal (Rp) }\end{array}$ & 51.818 .181 & 50.500 .000 & 53.000 .000 & 29.017 .857 & 21.500 .000 & 32.500 .000 \\
\hline $\begin{array}{l}\text { Rata-rata } \\
\text { penjualan }\end{array}$ & 588 & 500 & 660 & 327 & 200 & 500 \\
\hline $\begin{array}{l}\text { Rata-rata } \\
\text { pendapatan (Rp) }\end{array}$ & 28.000 .000 & 24.000 .000 & 32.000 .000 & 16.285 .714 & 12.000 .000 & 24.000 .000 \\
\hline $\begin{array}{l}\text { Keluhan } \\
\text { pelanggan }\end{array}$ & 4 & 2 & 5 & 3 & 2 & 4 \\
\hline $\begin{array}{l}\text { Cacat produk } \\
\text { tiap produksi }\end{array}$ & 381.82 & 200 & 500 & 335.71 & 200 & 500 \\
\hline $\begin{array}{l}\text { Wilayah } \\
\text { pemasaran }\end{array}$ & 4 & 2 & 5 & 3 & 2 & 3 \\
\hline \multicolumn{7}{|l|}{ Kualitas Produk } \\
\hline $\begin{array}{l}\text { Kinerja } \\
\text { (Performance) }\end{array}$ & 4.03 & 2.77 & 4.61 & 3.78 & 3.35 & 4.24 \\
\hline $\begin{array}{l}\text { Keandalan } \\
\text { (Reliability) }\end{array}$ & 2.80 & 2.21 & 3.48 & 2.62 & 2.10 & 3.22 \\
\hline $\begin{array}{l}\text { Keistimewaan } \\
\text { tambahan } \\
\text { (Feature) }\end{array}$ & 2.58 & 1.77 & 3.32 & 2.34 & 1.72 & 2.77 \\
\hline $\begin{array}{l}\text { Daya tahan } \\
\text { (Durability) }\end{array}$ & 4.22 & 3.75 & 4.75 & 3.96 & 2.67 & 4.55 \\
\hline
\end{tabular}


guatan kelembagaan diharapkan berperan serta dalam klaster industri. Keberhasilan pengembangan klaster sangat bergantung kepada hubungan kerjasama antar kelembagaan (Bembenek, 2015).

Hasil karakteristik responden UKM keripik gadung di Kecamatan Kalidawir dapat dilihat pada Tabel 2. Sebelum dilakukan analisis clustering dilakukan uji validitas dan reliabilitas hasil kuesioner penilaian kualitas. Indikator performance, reliability, feature dan durability memiliki nilai $r_{\text {hitung }}$ (Corrected ItemTotal Correlation) $>r_{\text {tabel }}$ sebesar 0.422 sehingga dapat dikatakan valid. Hasil uji validitas menunjukkan bahwa seluruh pernyataan yang dibuat dinilai layak dan dapat digunakan untuk keperluan penelitian (Kanichiro dan Sega, 2018). Hasil koefisien reliabilitas menunjukkan $r_{\text {alpha }}$ performance sebesar 0.642 , reliability 0.626 , feature 0.881 , dan durability 0.663 . Hal ini menunjukkan bahwa variabel memiliki nilai Alpha Cronbach $>0.600$, berarti keempat instrumen dinyatakan reliabel.

Rata-rata lama UKM beroperasi kurang lebih 13 tahun. Lama usaha berpengaruh terhadap pengalaman dari suatu usaha, dimana pengalaman dari usaha dapat mempengaruhi keberhasilan dari usaha itu sendiri (Omolayo dan Omole, 2013). Kapasitas produksi UKM keripik gadung rata-rata $5.416 \mathrm{~kg}$ per bulan

Kapasitas produksi salah satu tolak ukur yang penting dari suatu perusahaan (Vorotilin, 2009). Kapasitas produksi menentukan volume produk yang dihasilkan oleh perusahaan dalam suatu periode tertentu dengan menggunakan sumber daya (Ardalan et al., 1993).

Tenaga kerja yang digunakan UKM keripik gadung rata-rata sejumlah 7 orang. Tenaga kerja yang digunakan berasal dari anggota keluarga dan tetangga sekitar. Pentingnya tenaga kerja untuk meningkatkan produktivitas perusahaan (Saunders dan Tiwari, 2014). Apabila produktivitas meningkat maka output dan laba perusahaan diharapkan meningkat sehingga upah yang dibayarkan juga meningkat. Nilai investasi tiap UKM bervariasi tergantung kemampuan masing-masing UKM dalam mengakses dana. Rata-rata nilai investasi awal UKM keripik gadung sebesar $\mathrm{Rp} 39.050 .000,00$. Menurut Lailic et al. (2014), modal investasi digunakan ketika akan memulai usaha. Modal investasi awal nilainya cukup besar dan umumnya merupakan modal yang bisa dipakai dalam jangka panjang (Hellman, 2000). Rata-rata jumlah keluhan pelanggan sebesar $0.67 \%$ dari presentase jumlah keluhan pelanggan per bulan dibagi produk yang terjual. Keluhan pelanggan berupa komplain ketidakpuasan pelanggan yang disebabkan keterlambatan pengiriman produk, kecacatan produk dan kesalahan jumlah pesanan.

Menurut Bell dan Luddington (2006), keluhan pelanggan (customer complaints) berupa umpan balik (feedback) dari pelanggan yang ditujukan kepada perusahaan yang cenderung bersifat negatif. Umpan balik ini dapat dilakukan secara tertulis atau lisan (Simon et al., 2015).

Produk cacat yang dihasilkan UKM tiap produksi rata-rata sebesar $0.4 \%$. Kriteria produk cacat yaitu bentuk keripik tidak utuh atau remuk, aroma keripik berbau gosong, warna keripik coklat kehitaman dan keripik berjamur. Produk cacat yang dihasilkan dengan kriteria produk tidak sesuai dengan standar mutu, tetapi masih bisa di perbaiki dengan mengeluarkan biaya tertentu (Bettayeb et al., 2014).

Kegiatan penjualan yang dihasilkan UKM tiap bulan beragam, nilai rata-rata penjualan per bulan sebesar $444.44 \mathrm{~kg}$ dengan rata-rata pendapatan per bulan sebesar Rp 21.440.000,00. Penjualan memiliki dampak terhadap kemajuan dari suatu usaha. Semakin besar jumlah rata-rata penjualan maka tingkat keberhasilan suatu usaha semakin besar (Alhasan dan Sakara, 2014). Wilayah pemasaran tiap UKM rata-rata sejumlah 3 daerah. Menurut Kotler dan Kevin (1997), wilayah pemasaran merupakan sebuah tempat atau area dalam melakukan pemasaran agar dapat dilakukan distribusi produk.

Penilaian kualitas produk menggunakan skala likert (1-5), dengan kriteria sangat tidak sesuai (STS) hingga sangat sesuai (SS) semakin tinggi skala maka nilai semakin baik. Pengukuran kualitas produk menggunakan pendapat atau persepsi konsumen terhadap kualitas keripik gadung tiap UKM. Penilaian dimensi performance terdiri dari warna, aroma, tekstur, dan harga. Ratarata nilai performance produk keripik gadung sebesar 3.91 mendekati sesuai dengan standar SNI keripik gadung SNI 01-43021996 dari segi warna keripik gadung normal putih kekuning-kuningan, aroma keripik khas gadung, tekstur keripik normal sedikit kasar dan harga keripik terjangkau sesuai konsumen. Dimensi kinerja (performance) 
paling basic dan berhubungan dengan fungsi utama dari suatu produk (Garvin, 1987). Menurut Marique et al. (2007), peningkatan kinerja produk keripik dapat dinilai dari berbagai feature warna, ukuran, bentuk dan tekstur. Warna keripik merupakan atribut kualitas yang sangat penting dan mendasar untuk industri pengolahan pangan karena sangat terkait dengan persepsi konsumen (Scanlon et al., 1994). Tekstur merupakan atribut yang penting dalam menentukan tingkat kerenyahan. Salah satu faktor yang mempengaruhi tekstur keripik adalah jumlah air yang menguap pada saat pemasakan. Semakin banyak kadar air yang tidak teruapkan, maka volume pengembangan keripik akan semakin kecil dan terjadi keporosan keripik sehingga tingkat kerenyahan keripik menurun (Rosiani et al., 2015).

Penilaian dimensi reliability terkait tingkat kerapuhan dan kebersihan produk. Nilai rata-rata dimensi reliability sebesar 2.7 yaitu produk keripik gadung mendekati kurang sesuai dengan standar SNI 01-43021996 bahwa produk keripik gadung tidak boleh ada benda-benda asing dan keutuhan produk minimal 90\%, sedangkan produk yang dihasilkan sebagian masih kotor karena kemasan tidak tertutup rapat dan beberapa produk hancur atau remuk. Dimensi performance dan reliability sepintas terlihat mirip, tetapi mempunyai perbedaan yang jelas. Dimensi keandalan (reliability) terkait dengan konsistensi menunjukkan probabilitas produk gagal menjalankan fungsinya (Asghari et al., 2014). Kebersihan dan kualitas produk dapat dijaga dengan menggunakan kemasan yang tepat agar terhindar dari kotoran debu, udara, benturan dan sinar matahari serta sebagai media promosi yang dapat menarik minat pembeli (Dobermann et al., 2013).

Penilaian dimensi feature dilihat dari segi kemasan menarik bersifat informatif dan variasi bentuk produk. Nilai rata-rata dimensi feature sebesar 2.5, yaitu produk keripik gadung memiliki feature yang tidak sesuai karena kemasan tidak menarik, tidak memberikan informasi produk dan tidak ada variasi bentuk keripik sehingga minat daya beli konsumen rendah karena tidak inovatif. Dimensi feature merupakan karakteristik atau ciri-ciri tambahan yang melengkapi manfaat dasar suatu produk. Feature bersifat pilihan atau option bagi konsumen. Dimensi ini dikatakan sebagai aspek sekunder (Garvin,
1987). Kemasan produk merupakan aspek integratif produk dan faktor penting dalam keberhasilan atau kegagalan produk (Schoe1l, 1985). Komponen pengemasan mengacu pada wadah yang ditawarkan dan memberikan informasi terkait produk. Hal ini sangat penting bagi konsumen karena dapat menentukan keputusan pembelian (Abdalkarim dan Hrezat, 2013).

Penilaian dimensi durability dari segi umur simpan produk dan produk keripik tidak berjamur. Nilai rata-rata durability produk keripik gadung sebesar 4.1, yaitu daya tahan produk keripik gadung sesuai dari umur simpan produk, yaitu sekitar 1-1.5 tahun dan produk tidak mudah berjamur. Dimensi durability merupakan refleksi umur ekonomis berupa ukuran daya tahan atau masa pakai barang. Daya tahan memiliki keduanya, yaitu ekonomis dan teknis (Garvin, 1987). Daya tahan menunjukan usia produk, yaitu jumlah pemakaian suatu produk sebelum produk itu digantikan atau rusak. Semakin lama daya tahannya tentu semakin awet, produk yang awet akan dipersepsikan lebih berkualitas dibanding produk yang cepat habis atau cepat diganti (Karnes, 1995). Menurut Martina dan Asrina (2017), keripik mentah atau setengah jadi memiliki masa simpan yang lebih lama dibandingkan keripik yang sudah digoreng dikarenakan keripik yang sudah digoreng memiliki kandungan lemak yang tinggi.

\section{Penentuan Jumlah Klaster}

Analisis clustering menggunakan metode K-means clustering. Penentuan jumlah klaster dilakukan terlebih dahulu menggunakan metode elbow dapat dilihat pada Tabel 3. Tabel 3 menunjukkan bahwa perhitungan Sum Square Error (SSE) dilakukan sejumlah 4 klaster dengan asumsi bahwa skala usaha terdiri dari usaha mikro, kecil, menengah dan besar. Klaster yang mengalami penurunan selisih terbesar terletak pada klaster 2 sebesar 6.180695. Nilai withim sum of square by cluster dari $k=2$ nilainya sebesar $20.5 \%$, sedangkan $k=3$ nilainya sebesar $37.3 \%$. Penentuan jumlah klaster tergantung dari selisih SSE terbesar dan nilai withim of square by cluster yang terkecil. Semakin kecil nilai withim of squares maka cluster yang terbentuk semakin baik (Calinski dan Harabasz, 1974). Hasil analisis K-means menggunakan software SPSS menunjukkan bahwa minimal jarak antara pusat klaster (centroid) bernilai 8.804. 
Nilai pusat klaster 1 cenderung mendekati nilai minimal, nilai pusat klaster 2 cenderung mendekati nillai maksimal.

\section{Clustering UKM Keripik Gadung Berdasarkan Kinerja Industri Inti dan Kualitas Produk}

Perbedaan karakteristik klaster dapat dilihat pada Tabel 4. Perbedaan klaster tersebut digolongkan berdasarkan skala usaha mikro dan kecil (UMK), perbedaan skala usaha tergantung pada nilai investasi dan ratarata penjualan tahunan. Menurut UU Pasal 6 No. 2 Tahun 2008, usaha skala kecil memiliki kekayaan bersih lebih dari Rp 50.000.000,00 penjualan tahuan lebih dari Rp 300.000.000,00 dan jumlah tenaga kerja lebih dari 10 orang, usaha mikro memiliki kekayaan bersih maksimal Rp 50.000.000,00 dan hasil penjualan tahunan maksimal Rp 300.000.000,00 dengan jumlah karyawan kurang dari 10 orang.

\section{Klaster 1}

Klaster 1 tergolong usaha skala kecil terdiri dari 11 anggota UMK. Nilai Nilai investasi sebesar $\mathrm{Rp} 51.818 .181,00$ dan rata-rata penjualan $\mathrm{Rp} 28.000 .000,00$ per bulan. Ratarata tenaga kerja sejumlah 11 orang. Menurut Badan Pusat Statistik Nasional (BPS) dan UU No. 20 Tahun 2008 mendefinisikan jumlah tenaga kerja untuk usaha kecil di Indonesia terdiri dari 5-19 tenaga kerja. Perusahaan yang kurang dari 5 karyawan disebut home industry (Muditomo, 2012). Kategori jumlah tenaga kerja di Eropa untuk usaha mikro sejumlah 0-9 karyawan, usaha kecil sejumlah 10-49 karyawan (Commetrics, 2010; Schmiemann, 2010). Hal ini menunjukkan bahwa tiap negara memiliki perbedaan jumlah tenaga kerja untuk skala UMK.

Karakteristik klaster 1 sebagian UMK sudah memiliki sertifikat legalitas usaha berupa PIRT, sudah melakukan administrasi keuangan dan beberapa UMK telah mengakses ke perbankan dalam keperluan modal. Klaster 1 terdapat 4 anggota UMK yang mendapatkan bantuan pinjaman hutang dari Bank untuk modal usaha. Lama beroperasi usaha keripik gadung sekitar 16 tahun. Kapasitas produksi yang dihasilkan rata-rata $7000 \mathrm{~kg} /$ bulan.

Penjualan klaster 1 lebih tinggi dibanding klaster 2 rata-rata sebesar $588 \mathrm{~kg} /$ bulan dengan wilayah pemasaran sekitar Jawa Timur dan Kalimantan. Perusahaan yang sudah beroperasi cukup lama dan skala usaha yang besar memiliki pangsa pasar yang lebih besar (Karelakis et al., 2008). Usaha dapat bertahan lama karena memiliki fleksibilitas pasar dan daya saing pasar dalam menghadapi banyaknya persaingan usaha (Soekartawi, 1993). Dimensi kualitas produk menjadi pertimbangan dalam mengelompokkan UMK. Rata-rata nilai performance dan durability produk keripik gadung pada klaster 1 terletak pada skala 4.03 dan 4.22 menunjukkan bahwa nilai performance dan durability sesuai dengan standar SNI 01-4302-1996, nilai reliability pada klaster 1 sebesar 2,80 mendekati skala 3 yaitu nilai reliability kurang sesuai dari segi kebersihan, kerapuhan dan kerapatan kemasan. Rata-rata nilai feature klaster 1 sebesar 1.72 mendekati skala 2 bahwa nilai feature tidak sesuai dengan kemasan yang mudah sobek dan kurang menarik, tidak bersifat informatif dan bentuk produk tidak variatif.

Pada klaster 1 tingkat kinerja lebih tinggi dan sudah cukup berpengalaman sehingga anggota klaster 1 dapat mengetahui kondisi pasar. Pengalaman dan penguasaan pasar yang tinggi menghasilkan penjualan yang lebih besar dan kemampuan memperoleh laba yang tinggi dibandingkan klaster 1. Pada tingkat kualitas produk, klaster 1 masih rendah dilihat dari nilai feature dan reliability pada kisaran skala 2 tidak sesuai dengan standar SNI dan pernyataan pada kuesioner.

Penerapan klaster pada UMK keripik gadung dapat meningkatkan akses yang lebih mudah ke sumber daya, UMK dapat berkonsentrasi dengan aktivitas di bidang yang sama sehingga dapat menciptakan tenaga kerja yang memiliki pengalaman khusus dibidangnya, adanya kedekatan industri yang sama memungkinkan pertukaran pengetahuan dan ide melalui komunikasi secara langsung atau pertukaran tenaga kerja (Boja, 2011). Keuntungan clustering dapat mengurangi biaya pengiriman bahan baku dimana terdapat 1 anggota UMK Bu Ponirah sebagai pengepul bahan baku sehingga anggota UMK klaster 1 tidak perlu memesan bahan baku dari luar sehingga lebih efektif dan efisien. Adanya clustering dapat membangun hubungan jaringan antar elemen sehingga memberikan keuntungan dalam mengakses pertukaran informasi terkait sumber daya, teknologi dan dorongan inovasi yang berdampak pada peningkatan produktivitas dan perbaikan produk (Lei dan Huang, 2014). 


\section{Klaster 2}

Klaster 2 tergolong usaha skala mikro yang terdiri dari 14 anggota UMK. Nilai investasi klaster 2 sebesar Rp 29.017.857,00 dan rata-rata penjualan sebesar $\operatorname{Rp} 16.285 .714,00$. Rata-rata jumlah tenaga kerja sebanyak 5 orang. UMK klaster 2 memiliki jumlah tenaga kerja $\leq 10$ orang. Modal yang digunakan selama ini masih menggunakan dana pribadi sehingga sebagian UMK keterbatasan modal. Beberapa kalangan banyak yang berasumsi bahwa UMK tidak memiliki potensi untuk didanai oleh lembaga keuangan formal. Kelompok usaha tersebut dinilai tidak layak bank (not bankable) karena tidak memiliki jaminan atau agunan, serta diasumsikan kemampuan mengembalikan pinjamannya rendah dan mahalnya biaya transaksi. Akibat asumsi tersebut, maka aksesibilitas dari UKM terhadap sumber keuangan formal rendah (Liu dan Shih, 2005).

Karakteristik klaster 2 rata-rata belum memiliki sertifikat legalitas usaha, belum melakukan administrasi keuangan dengan baik dan belum mengakses ke perbankan dalam keperluan modal. Menurut Rijanto dan Sarwono (2015), karakteristik usaha mikro umumnya tidak memiliki izin usaha atau persyaratan legalitas dan belum melakukan administrasi keuangan walau sederhana. Menurut Radomír et al. (2013), karakteristik produk yang dihasilkan dari usaha kecil dan mikro (UMK) yaitu kualitas belum standar karena sebagian besar UMK belum memiliki kemampuan teknologi yang memadai, desain produk terbatas karena keterbatasan pengetahuan dan pengalaman mengenai produk dan bahan baku tidak standar karena bahan baku diperoleh dari berbagai sumber yang berbeda.

Lama beroperasi pada klaster 2 sekitar 12 tahun dengan rata-rata kapasitas produksi $4.171 \mathrm{~kg} /$ bulan. Rata-rata penjualan klaster 2 sebesar $327 \mathrm{~kg} /$ bulan. Rata-rata penjualan klaster 2 lebih sedikit dikarenakan UMK klaster 2 memiliki pengalaman yang lebih sedikit dibanding klaster 1 . Selain itu, kegiatan pemasaran hanya dilakukan secara individu tidak melibatkan distributor atau retailer sehingga jangkauan pemasaran masih terbatas. Wilayah pemasaran yang dilakukan anggota klaster 2 sekitar Jawa Timur. Menurut Nainggolan (2016), tingkat pendapatan dipengaruhi lama usaha karena lamanya seorang pelaku usaha atau bisnis menekuni bidang usahanya akan mempengaruhi produktivitasnya atau keahliannya, sehingga dapat menambah efisiensi dan mampu menekan biaya produksi lebih kecil dari pada hasil penjualan.

Rata-rata dimensi performance klaster 2 sebesar 3.78 mendekati skala 4 yaitu nilai performance klaster 2 mendekati sesuai dengan standar SNI 01-4302-1996 dari segi aroma, tekstur dan warna keripik gadung. Nilai reliability klaster 2 sebesar 2.10 mendekati skala 2, tidak sesuai dengan standar SNI karena masih terdapat kotoran pada produk seperti debu dan kerikil, sebagian produk rapuh atau hancur, dan kemasan tidak tertutup rapat. Nilai feature klaster 2 sebesar 2.34 menunjukkan nilai mendekati skala 2 berarti feature keripik gadung menurut responden tidak sesuai dari segi kemasan yang mudah sobek dan kurang menarik, kemasan tidak bersifat informatif dan bentuk produk tidak variatif. Nilai durability produk keripik gadung klaster 2 sebesar 3.96 mendekati skala 4, menunjukkan nilai durability sesuai dengan umur simpan produk sekitar 1-1.5 tahun dan produk tidak berjamur.

Pada klaster 2 tingkat kinerja dan kualitas produk yang dihasilkan lebih rendah dibanding klaster 1, hal ini disebabkan karena klaster 1 sebagian besar masih berjalan individu, kurang komunikasi serta pengalaman yang dimiliki masih rendah. Akses pemasaran dan jumlah tenaga kerja terbatas karena kekurangan sejumlah modal. Oleh maka dari itu, UMK klaster 2 perlu memanfaatkan kedekatan lokasi dengan anggota klaster dalam menggunakan input (informasi, teknologi atau akses supplier) dan meningkatkan inovasi serta kerjasama dengan Pemerintah dalam mengakses kebutuhan modal usaha. Kemampuan inovatif memungkinkan UKM untuk mengembangkan produk baru dengan biaya lebih rendah (Pickernell et al., 2010).

\section{Variabel Pembeda Uji Beda Rata-rata}

Analisis statistik uji beda rata-rata (ujit) digunakan untuk menguji perbedaan nilai variabel masing-masing klaster. Hasil perhitungan menunjukkan bahwa variabel kinerja yang berbeda signifikan antar klaster 1 dan 2 (kapasitas produksi, tenaga kerja, nilai investasi, penjualan produk, dan pendapatan usaha) dengan nilai sebesar 0.00 atau $<0.05$, sedangkan variabel yang tidak berbeda signifikan atau tidak berbeda jauh variabel (lama usaha, keluhan pelanggan, jumlah cacat dan jumlah wilayah pemasaran) dengan 
nilai $>0.05$. Uji sampel $t$-test pada variabel kualitas terdiri dari dimensi performance dan feature sebesar 0.15 , dimensi reliability sebesar 0.26 dan dimensi durability sebesar 0.11 , hal ini menunjukkan bahwa nilai variabel kualitas $>0.05$ yaitu kualitas produk klaster 1 dan 2 tidak ada perbedaan yang signifikan.

\section{Usulan Perbaikan}

Berdasarkan permasalahan yang dihadapi UMK keripik gadung di Kabupaten Tulungagung, maka diperlukan upaya perbaikan yang sesuai dengan kondisi masingmasing klaster. Pada klaster 1 upaya peningkatan kinerja dapat dilakukan dengan meningkatkan kerjasama antar UMK dalam pemesanan bahan baku kepada pengepul UMK Ibu Ponirah agar tidak terjadi kesalahan pemesanan dan mengurangi biaya pengiriman. Selain itu, diperlukan peningkatan akses pertukaran informasi terkait pemasaran dan dorongan inovasi teknologi yang berdampak pada peningkatan produktivitas dan kualitas produk.

Peningkatan kualitas produk klaster 1 melalui perbaikan pada feature produk dengan melakukan inovasi variasi bentuk produk dan perbaikan kemasan. Inovasi menciptakan berbagai desain produk sehingga dapat meningkatkan alternatif pilihan dan manfaat yang berdampak pada peningkatan kualitas. Peningkatan inovasi membutuhkan teknologi modern karena mempengaruhi kecepatan produktivitas usaha. Teknologi modern yang dibutuhkan UMK adalah mesin perajang, mesin pengering dan mesin pengemas handsealer. Inovasi mampu membuat produk yang berbeda, sehingga konsumen lebih tertarik membeli produk tersebut dibandingkan dengan produk pesaing (Fain et al., 2011). Produk yang berkualitas akan meningkatkan keunggulan bersaing dan berdampak pada peningkatan kinerja perusahaan (Reguia, 2014).

Usulan perbaikan yang dapat dilakukan klaster 2 untuk meningkatkan kinerja UMK melalui peningkatan akses permodalan dan membentuk salah satu UMK yang menjadi pengepul bahan baku, sehingga UMK lainnya dapat mengambil bahan baku di pengepul agar ebih efektif dan efisien. Peningkatan akses pemodalan menjadi prioritas utama karena UMK klaster 2 masih menggunakan modal pribadi yang jumlahnya terbatas. UMK klaster 2 dapat melakukan kerjasama dengan Pemerintah atau instansi lain (Bank) untuk memperoleh akses permodalan. Pemodalan dapat digunakan untuk biaya peningkatan strategi pemasaran, peningkatan kapasitas produksi, pembelian mesin dan peralatan dan perbaikan kualitas produk. Hal ini akan berdampak pada kinerja perusahaan yang semakin meningkat. Keberhasilan usaha kecil dan mikro tidak lepas dari peran Pemerintah dalam mendorong penyaluran kredit kepada UMKM. Penguatan pemodalan dapat memanfaatkan keberpihakan Pemerintah berupa penyedia bantuan dan ketersediaan dana (Ruslan, 2007).

Peningkatan kualitas produk klaster 1 dan 2 diperlukan standarisasi yang sesuai dengan SNI 01-4302-1996 dan pelaksanaan quality control (QC). Penerapan SNI memerlukan biaya yang cukup besar dan teknologi salah satu kunci dalam upaya pelaksanaan standarisasi mutu produk. Pelaksanaan QC dapat dilakukan mulai dari proses pemilihan bahan baku, proses produksi dan produk akhir. Penerapan standarisasi produk dan pelaksanaan QC sangat penting untuk meningkatkan daya saing dan mengurangi beberapa permasalahan terkait kecacatan produk yang menyebabkan keluhan pelanggan (Hubeis, 1999).

Peningkatan akses pemasaran perlu dilakukan dengan menciptakan inovasi strategi pemasaran yang tepat untuk meningkatkan penjualan produk. Akses pemasaran akan lebih mudah ditingkatkan jika produk yang dipasarkan memiliki kualitas dan standarisasi yang baik serta dapat diterima pasar. Peningkatan akses pemasaran dapat melalui perluasan jaringan kerjasama dengan pemerintah atau instansi terkait dan meningkatkan kualitas dengan memperhatikan atribut produk, seperti tampilan fisik, kualitas rasa produk dan kemasan. Strategi promosi yang dilakukan home industry atau usaha kecil mikro belum banyak dilakukan bila dibandingkan dengan produk pangan hasil industri besar disebabkan karena biaya promosi yang umumnya relatif terbatas (Kim et al., 2003). Terbatasnya akses pemasaran dapat menyebabkan produk yang dihasilkan tidak dapat dipasarkan secara kompetitif (Brucks et al., 2000).

Perbaikan tersebut melibatkan seluruh pelaku klaster dan pihak pemerintah daerah terkait. Pemerintah diharapkan dapat memfasilitasi dan mempermudah birokasi. Pembinaan dan pengembangan dapat dilakukan dalam bentuk program mitra binaan yang 
bekerjasama dengan Lembaga penelitian dan pengembangan (Litbang) serta perguruan tinggi (PT). Peran perguruan tinggi (PT) sangat penting terkait riset pengembangan klaster keripik gadung dalam hal produk, proses produksi, inovasi dan teknologi dan menyelenggarakan kursus atau pelatihan pengembangan usaha terutama fokus pada bisnis dan manajemen yang menyediakan platform bagi manajer atau wirausaha untuk meningkatkan pengetahuan.

\section{SIMPULAN}

UKM keripik gadung di Kecamatan Kalidawir Kabupaten Tulungagung memiliki potensi untuk dikembangkan. Jumlah UKM yang aktif produksi sekitar 25 UKM. Hasil analisis klaster UKM keripik gadung berdasarkan kinerja dan kualitas produk menggunakan metode K-means cluster membentuk 2 klaster. Klaster 1 terdiri dari 11 anggota dan klaster 2 terdiri dari 14 anggota. Klaster 1 termasuk skala usaha kecil dan klaster 2 termasuk skala usaha mikro. Perbedaan skala usaha dilihat dari nilai investasi dan rata-rata penjualan tahunan. Klaster 1 memiliki kinerja lebih tinggi dibanding klaster 2, namun kualitas produk masih tergolong rendah, sedangkan klaster 2 nilai kinerja dan kualitas masih rendah. Alternatif utama untuk pengembangan usaha klaster 1 melalui peningkatan kerjasama antar UMK dalam akses pembelian bahan baku dan peningkatan inovasi teknologi, sedangkan klaster 2 melalui peningkatan permodalan dan membentuk tim koordinasi untuk pembelian bahan baku. Peningkatan akses pemasaran, penerapan standarisasi serta quality control (QC) perlu dilakukan klaster 1 dan 2 karena untuk meningkatkan daya saing diperlukan produk yang berkualitas dan kegiatan pemasaran yang tepat. Upaya perbaikan melibatkan seluruh pelaku dan Pemerintah daerah yang saling terhubung dan bekerjasama sehingga dapat mencapai keberhasilan usaha.

\section{DAFTAR PUSTAKA}

Abdalkarim, G, -M., Hrezat, R, -S., 2013. The role of packaging in consumer's perception of product quality at the point of purchase. European Journal of Business and Management. 5, 69-82. https:// pdfs.semanticscholar.org/4cbd/4c0c2 7392287b0ff184189fbc2602d5a0bac.pdf

Akhmad, -S., Hidayat, -R., 2014. Cluster industri kecil menengah berdasarkan kinerja supply chain. Jurnal Rekayasa Sistem Industri. 3, 36-45. https://doi. org/10.26593/jrsi.v3i2.1295.36-45

Alhasan, -F., Sakara, -A., 2014. A study into the effects of sales promotion on polytechnic students' choice of telecommunication network in ghana: a case study of tamale polytechnic. The International Journal of Business \& Management. 2, 1-22. http://www.internationaljournalcorner.com/index.php/ theijbm/article/view/132462

Ardalan, A., Pope, J, -A., Hammesfahr, R, D, -J., 1993. Strategic planning for production capacity. International Journal of Operations \& Production Management. 13, 41-53. https://doi. org/10.1108/01443579310028166

Arzhakov, A, -V., Silnov, D, -S., 2016. New approach to designing an educational automated test generation system based on text analysis. ARPN Journal of Engineering and Applied Sciences. 11, 261-265. http://www.arpnjournals. org/jeas/research_papers/rp_2016/ jeas_0316_3748.pdf

Asghari, -M., Jusoh, -A., Kianpour, -K., 2014. Environmentally friendly as a new dimension of product quality. International Journal of Quality \& Reliability Management. 31, 547-565. https://doi. org/10.1108/IJQRM-06-2012-0079

Bappeda Jawa Timur. 2018. Dokumentasi Hasil Pelaksanaan dan Pembangunan Kabupaten Se-Jawa Timur. Dilihat 10 Januari 2019. http://bappeda.jatimprov.go.id/bappeda/publikasi/dok_ kabkota_jatim_2018.pdf

Bembenek, -B., 2015. The sustainable development of an industrial cluster in the context of corporate social responsibility-a new challenge for cluster management. European Scientific Journal. 1, 225-235. https://eujournal.org/index. $\mathrm{php} / \mathrm{esj} /$ article/viewFile/5090/4862

Bernat, -J., Wright, L, -W., Adams, H, -E., 1999. Development and validation of the homophobia scale. Journal of Psychopathology and Behavioral Assessment. 21, 337-347. https://doi. 
Jurnal Teknologi Pertanian Vol. 20 No. 1 [April 2019] 53-66

Analisis Klaster UKM Keripik Gadung [Zakiyah dkk]

org/10.1023/A:1022172816258

Bettayeb, -B., Baseeto, -J., Sahnoun, M. 2014. Quality control planning to prevent excessive scrap production. Journal of Manufacturing Systems. 33, 400-411. https://doi.org/10.1016/j. jmsy.2014.01.001

Boja, -C., 2011. Cluster models, factors and characteristics. International ournal of Economic Practices and Theorities. 1, 3443. http://www.ijept.org/index.php/ ijept $\% 20 /$ article/view $/ 8$

BPS. 2018. Badan pusat statistik kabupaten tulungagung. Diliihat 31 Januari 2019. https:/ / tulungagungkab.bps.go.id/ statictable/2018/05/03/2632/letakgeografis-batas-wilayah-atau-daerahdan-luas-wilayah-kecamatan-kalidawir-2016.html

Brucks, -M., Zeithaml, V, -A., Naylor, -G., 2000. Price and brand name as indicators of quality dimensions for consumer durables. Journal of the Academy of Marketing Science. 28, 359-374. https:/ / doi.org/10.1177/0092070300283005

Calinski, -T., Harabasz, -J., 1972. A Dendrite Method for Cluster Analysis. Journal Communication in Statistics, 3, 1-27. https:/ / www.tandfonline.com/doi/ abs/10.1080/03610927408827101

Commetrics. 2010. European commission: defining the SME. Dilihat 28 Maret 2018. http://commetrics.com/articles/european-commssion-definingthe-term-sme/

Djafar, Z, -R., 2013. Kegiatan agronomis untuk meningkatkan potensi lahan lebak menjadi sumber pangan. Jurnal Lahan Suboptimal. 2, 58-67. https://doi. org/10.33230/JLSO.2.1.2013.28

Dobermann, A., Nelson, R., Beever, D., Bergvinson, D., Crowley, E., Denning, G., Giller, K., Hughes, J., Jahn, M., Lynam, J. 2013. Solutions for Sustainable Agriculture and Food Systems, Technical Report for the Post-2015 Development Agenda; Thematic Group on Sustainable Agriculture and Food Systems of the Sustainable Development Solutions Network. Food Systems Development (Center for Transformative Action) Inc, New York

Doncheva, -D., 2016. Cluster-way for increasing the competitiveness of regions. Trakia Journal of Sciences. 14, 275-280. http:/ / tru.uni-sz.bg/tsj/Vol.14,\%20 N\%203,\%202016/D.Don4eva.pdf
Fain, -N., Kline, -M., Duhovnik, -J., 2011. Integrating R\&D and marketing in new product development. Strojniški vestnik - Journal of Mechanical Engineering. 57, 599-609. http://dx.doi.org/10.5545/ sv-jme.2011.004

Garvin, D, -A., 1987. Competing on the eight dimensions of quality. Journal Harvard Business Review. 65, 101-109. https:// hbr.org/1987/11/competing-on-theeight-dimensions-of-quality

Genty, K, -I., Idriss, -K., Wahat, N, A, -W., Kadir, A, -S., 2015. Demographic factors as predictor of entrepreneurs' success and micro small and medium enterprises (MSMEs) owners in lagos state in nigeria. IOSR Journal of Business and Management. 17, 125-132. http:// dx.doi.org/10.9790/487X-17112125132

Hellman, -T., Puri, -M., 1999. The interaction between product market and financing strategy: the role of venture capital. Sauder School of Business Working Paper. 13, 959-984. https://dx.doi. org/10.2139/ssrn.173655

Hirohata, $-\mathrm{N} ., 2$ 2013. One village one product (OVOP) movement in laos. International Journal of Engineering Innovation and Management. 3, 31-35. http://web. cc.yamaguchi-u.ac.jp/ eimanage/ vol3issue2/OVOP-Hirohata-31-35.pdf

Hubeis, M. 1999. Sistem Jaminan Mutu Pangan. Pelatihan Pengendalian Mutu dan Keamanan Bagi Staf Pengajar. IPB, Bogor

Hudzari, R, -M., Ssomad, M, -A., Rizuwan, Y, -M., Asimi, M, -N., Abdulloh, A, -B., Fauzan, M, -Z., 2011. Modification of automatic alkaloid removal system for dioscorine. International Journal of Agronomy and Plant Production. 2, 155161. https://www.semanticscholar. org/paper/Modification-of-automatic-alkaloid-removal-system-HudzariSsomad/0b7abbf04d25f834a57629315 78fab0da7699c91

Jain, A, -K., 2010. Data clustering: 50 years beyond K-means. Pattern Recognition Letters. 31, 651-666. https://doi. org/10.1016/j.patrec.2009.09.011

Kanichiro, -S., Sega, N, -J., 2016. The OVOP as a tool to develop small and mediumsized enterprises: insights from OVOP entrepreneurial experience in senegal. International Journal of Education and Research. 6, 95-112. https://www.ijern. com/journal/2018/March-2018/12. 


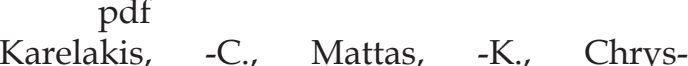
soschoidis, -G., 2008. Export problems perceptions and clustering of greek wine firms. EuroMed Journal of Business. 3, 6-22. https://doi. org/10.1108/14502190810873795

Karnes, C.L., VSridharan, -S., Kanet, J, -J., 1995. Measuring quality from the consumer's perspective: a methodology and its application. International Journal of Production Economics. 39, 215225. https://doi.org/10.1016/09255273(95)00027-L

Kim, -C., Kim, -S., Im, -S., Shin, -C., 2003. The effect of attitude and perception on consumer complaint intentions. Journal of Consumer Marketing. 20, 352-371. https://doi. org/10.1108/07363760310483702

Kotler, P, Kevin, LK. 1997. Manajemen Pemasaran. Erlangga, Jakarta

Lailic, -M., Horvat, -J., Calopa, M, K., 2014. Analysis of Financing Sources For Start-Up Companies. Journal of Management. 19, 19-44. https://moj.efst. $\mathrm{hr} /$ management/Vol19No2-2014/3KlacmerCalopa_et_al.pdf

Lei, H, -S., Huang, C, -H., 2014. Geographic clustering, network relationships and competitive advantage. Management Decision. 52, 852-871. https://doi. org/10.1108/MD-08-2013-0426

Liu, D, -R., Shih, Y, -Y., 2005. Integrating AHP and data mining for product recommendation based on customer lifetime value. Information $\mathcal{E}$ Management. 42, 387-400. https://doi.org/10.1016/j. im.2004.01.008

Maduekwe, C, -C., Kamala, -P., 2016. Performance measurement by SMEs in cape metropolis south africa. Problem and Perspective in management 14, 46-55. https://doi.org/10.21511/ ppm.14(2).2016.05

Marique, T, Mery, D, Pedreschi, F. 2007. 'Quality Evaluation and Control of Potato Chips and French Fries'. Dalam Sun DW. Computer Vision Technology for Food Quality Evaluation. Elsevier, USA

Martina, Asrina., 2017. Strategi pemasaran usaha kerupuk tempe di desa blang geulanggang kecamatan peusangan kabupaten bireuen (studi kasus: usaha kerupuk tempe ibu yusnita). Jurnal
Sains Pertanian. 1, 48-62. http://jurnal. umuslim.ac.id/index.php/JSP/article/view/781

Mustaniroh, S, -A., Amalia, -F., Effendi, -M., Effendi, -U., 2016. Strategi pengembangan klaster keripik apel dengan K-means clustering dan analytical hierarchy process. Industria, Jurnal Teknologi dan Manajemen Agroindustri. 5, 67-74. https://doi.org/10.21776/ ub.industria.2016.005.02.3

Muditomo, A. 2012. Mencermati peran pemerintah dalam pengembangan koperasi dan UMKM di indonesia. Majalah Bank Manajemen.

Nad, -I., Adelsberger, -Z., Buntak, -K., 2012. Impact of product quality in the business of the organization. International Journal for Quality research. 6, 271-283. http://www.ijqr.net/journal/v6n3/10.pdf

Nainggolan, -R., 2016. Gender, tingkat pendidikan dan lama usaha sebagai determinan penghasilan UMKM kota surabaya. Jurnal Kinerja. 20, 1-12. https:/ / doi.org/10.24002/kinerja.v20i1.693

Omolayo, -B., Omole, -O., 2013. Influence of mental workload on job performance. International Journal of Humanities and Social Science. 3, 238-246. http:/ / www. ijhssnet.com/journals/Vol_3_No_15_ August_2013/27.pdf

Porter, M, -E., 1998. Cluster and new economics of competition. Dilihat 10 Januari 2019. https://hbr.org/1998/11/ clusters-and-the-new-economics-ofcompetition

Pickernell,-D., Packham,-G., Brooksbank,-D., Jones, -P., 2010. A recipe for what? UK universities, enterprise and knowledge transfer: evidence from the federation of small businesses 2008 survey. The International Journal of Entrepreneurship and Innovation. 11, 265-272. https:// doi.org/10.5367\%2Fijei.2010.0001

Radomir, -P., Adam, -P., Karel, -S., 2013. Strategic planning and business performance of micro, small and medium-sized enterprises. Journal of Competitiveness. 5, 57-72. https://www. cjournal.cz/files/151.pdf

Reguia, -C., 2014. Product innovation and the competitive advantage. European Scientific Journal 1, 140-157. http:/ / dx.doi. org/10.19044/esj.2014.v10n10p\%25p

Richard, J, -P., Davinney, T, -M., Yip, G, 
-S., Johnson, -G., 2009. Measuring organisational performance toward methodology best Practice. Journal of Management. 35, 718-809. https://doi. org/10.1177\%2F0149206308330560

Rijanto, E, Sarwono, H. 2015. Profil usaha mikro, kecil dan menengah (UMKM). Dilihat 10 Januari 2019. https://www. bi.go.id/id/umkm/penelitian/nasional/kajian/Documents/Profil\%20 Bisnis\%20UMKM.pdf

Ruslan, R. 2007. Manajemen Public Realtions $\mathcal{E}$ Media Komunikasi: Konsepsi dan Aplikasi. Raja Grafindo Persada, Jakarta

Saunders, -L., Tiwari, -D., 2014. Employee engagement and disengagement: causes and benefit. The International Journal of Business and Management. 2, 44-52. http://internationaljournalcorner.com/index.php/theijbm/article/view/127647/88407

Scanlon, M, -G., Roller, -R., Mazza, -G., Pritchard. 1994. Computerized video image analysis to quantify color of potato chips. American Potato Journal. 71, 717-733. https://doi.org/10.1007/ BF02849210

Schumann, R, F. 2016. A study of one village one product (OVOP) and workforce development: lessons for engaging rural communities around the world. Dilihat 10 Januari 2019. https://www. jil.go.jp/profile/documents/f.chumann.pdf

Soekartawi. 1993. Agribisnis : Teori dan Aplikasinya. Raja Grafindo Persada, Jakarta

Trimanto, Hapsari, -L., 2015. Diversity and utilization of Dioscorea Spp. Tuber as alternative food source in nganjuk regency, east java. Agrivita. 37, 97-107. https:/ / doi.org/10.17503/ Agrivita2015-37-2-p097-107

Simon, -A., Kafel, -P., Nowicki, -P., Casadesus, -M., 2015. The development of complaints handling standards in spa companies: a case study analysis in spain. International Journal for Quality Research. 9, 675-688. https://www.researchgate.net/ publication/287533734_The_development_of_complaints_handling standards_in_spa_companies_A_ case_study_analysis_in_Spain

Sunarish, E, -S., Djatmika, Utomo, R, -S., 2007. Influence of administration of gadung corm (Dioscorea hipsida Dennst) influsion to decrease of blood glucose level at aloksan inducted male diabetic rats. Majalah Farmasi Indonesia. 18, 2933. http://dx.doi.org/10.14499/indonesianjpharm0iss0pp29-33

Vorotilin, B. 2009. Production Capacity Function In Manufacturing. Tesis. Kyiv School of Economics. Ukraina

Webster, -J., Beck, -W., Ternai, -B., 1984. Toxicity and bitterness in Australian Dioscorea bulbifera L. and Dioscorea hispida Dennst. from Thailand. Journal of Agricultural and Food Chemistry. 32, 1087-1090. https://doi.org/10.1021/ jf00125a039

Rosiani, -N., Widowati, E., Basito., 2015. Kajian karakteristik sensoris fisik dan kimia kerupuk fortifikasi daging lidah buaya (aloe vera) dengan metode pemanggangan menggunakan microwave. Jurnal Teknologi Hasil Pertanian. 8, 84-98. http://dx.doi.org/10.20961/ jthp.v0i0.12896

Yee, R, W, -Y., Yeung, A, C, -L., Edwin, C, -T., 2010. An empirical study of employee loyalty, service quality and firm performance in the service industry. International Journal of Production Economics. 124, 109-120. https://doi. org/10.1016/j.ijpe.2009.10.015

Zhukov, -B., Gorynya, E, -V., Ivanova, E, -A., Borobov, -V., Dorodina, -I., 2016. Agro-industrial clusters as a factor of increasing competitiveness of the region. International Journal of Economics and Financial. 6, 295-299. https:// www.econjournals.com/index.php/ ijefi/article/view/2402 